\title{
Anti-inflammatory, antioxidant, and antimicrobial activities of Cocos nucifera var. typica
}

\author{
Rafaela Ribeiro Silva', Davi Oliveira e Silva ${ }^{1}$, Humberto Rollemberg Fontes ${ }^{3}$, Celuta Sales Alviano ${ }^{1}$, \\ Patricia Dias Fernandes ${ }^{2^{*}}$ and Daniela Sales Alviano ${ }^{1}$
}

\begin{abstract}
Background: Teas from the husk fiber of Cocos nucifera are used in the folk medicine to treat arthritis and other inflammatory processes. Some works show that some varieties have biological activities. However, one of the main variety of the species, C. nucifera var. typica, known in Brazil as "gigante", was not studied yet. Thus, this study evaluates if this variety has the anti-inflammatory and antimicrobial activities already reported in other varieties.

Methods: $C$. nucifera aqueous crude extract $(10,50$, and $100 \mathrm{mg} / \mathrm{kg})$ and the reference drugs morphine $(1 \mathrm{mg} / \mathrm{kg})$ and acetylsalicylic acid $(100 \mathrm{mg} / \mathrm{kg}$ ) were evaluated in models of inflammation (formalin-induced licking and subcutaneous air pouch). The antioxidant activity was evaluated by 2,2-diphenyl-1-picryl-hydrazyl-hydrate (DPPH) photometric assay and compared with those of the standards (quercetin, rutin, and ascorbic acid). The extract was also screened against Candida albicans, Escherichia coli, Staphylococcus aureus, and methicillin-resistant Staphylococcus aureus (MRSA), in the agar diffusion method. The minimal inhibitory concentration (MIC) and minimal bactericidal concentration (MBC) were determined by the broth micro-dilution assay. Activities of combinations of the extract and antibiotics (methicillin or vancomycin) against MRSA were evaluated using checkerboard assays.
\end{abstract}

Results: The extract significantly inhibited the time that the animals spent licking the formalin-injected paws (second phase). The extract also inhibited the inflammatory process induced by subcutaneous carrageenan injection by reducing cell migration, protein extravasation, and TNF-a production. Additionally, the extract showed an antioxidant potential in vitro as good as standards in their antioxidant activity. The extract was active only against $S$. aureus and MRSA. MIC and the bactericidal concentrations were identical $(1,024 \mathrm{\mu g} / \mathrm{ml})$. The extract and methicillin acted synergistically against the clinical MRSA isolate, whereas an indifferent effect was detected when the extract was combined with vancomycin.

Conclusions: The extract exhibits anti-inflammatory activity through the inhibition of the cell migration. The mixture of extract constituents and methicillin could lead to the development of a new combination antibiotic against MRSA infections.

Keywords: Cocos nucifera, Anti-inflammatory activity, Antioxidant activity, Antimicrobial activity

\section{Background}

The varieties of Cocos nucifera are found all over the tropical regions. In Brazil, there are different varieties like the "gigante" [1]. The aqueous crude extract of husk fiber from C. nucifera is widely used in northeastern Brazilian traditional medicine to treat diarrhea and arthritis [2]. During the past years, it has been shown that the "comum"

\footnotetext{
* Correspondence: patricia.dias@icb.ufrj.br

${ }^{2}$ Universidade Federal do Rio de Janeiro, Instituto de Ciências Biomédicas, Laboratório de Farmacologia da Dor e da Inflamação, Rio de Janeiro, Brasil Full list of author information is available at the end of the article
}

C. nucifera has antibacterial, antiviral [2], antioxidant [3], anti-neoplastic $[4,5]$, and anti-inflammatory activities [6].

The variety "anão" is divided in "green", "yellow" and "red". The "mestiço" are known as segregated hybrids, resulting from aleatory cross between diverse plants, and thereby with unknown origin [1].

The inflammatory process is a complex phenomenon from vascular tissues to harmful stimuli, such as pathogens, damaged cells or irritants [7]. In this paper, the antiinflammatory action of an aqueous crude extract of husk fiber from C. nucifera was assessed in two animal models. 
Since, reactive oxygen species (ROS) have been implicated as novel second messengers that help regulate cellular events like inflammation [8], the free radical scavenging properties was either evaluated.

Besides the antioxidant and anti-inflammatory activities, the antimicrobial action was also evaluated by antibacterial and antifungal activities assays in this study, once the antimicrobial properties of the aqueous extracts of husk fiber from another Brazilian and Nigerian C. nucifera varieties were previously described $[2,9]$. Since combination therapies may results in the administration of a lower dose of commercial antimicrobials, which might reduce drug toxicity and improve efficacy [10], combinations of the $C$. nucifera extract and commercial antimicrobials were also performed in this paper.

Considering that previous studies demonstrated the low toxicity of aqueous crude extract of husk fiber from other varieties of $C$. nucifera $[3,6]$, this is also expected for the "gigante" variety. In the popular use of this plant extract, the occurrence of adverse effects is not documented and aqueous crude extracts generally have low acute toxicities [11].

Furthermore, the use of the husk fiber might lead to the production of novel low-cost therapies and adjunct treatments because it is a by-product from the processing of C. nucifera [6]. Therefore, the purpose of this study was to evaluate the anti-inflammatory, antioxidant and antibacterial activities of a variety of $C$. nucifera that has not been investigated yet, the "gigante".

\section{Materials and methods Plant material}

C. nucifera (Arecaceae) var. typica, commonly known as "gigante", was collected in Sergipe, Brazil (Campo Experimental de Itaporanga, Embrapa Tabuleiros Costeiros) and authenticated by the forest engineer Humberto Rollemberg Fontes (Fitotecnia researcher). The characterization and identification of this variety was done following morphological, phenological, and production aspects of the plant, in addition to other criteria, such as age of the plant [12]. A voucher specimen was deposited (number ASE- 27,441) at the Federal University of Sergipe.

\section{Preparation of $C$. Nucifera crude extract}

The water extract from husk fiber was prepared by infusion, as described previously [2]. The use of aqueous extract was in accordance with the popular medicinal knowledge. The extract was filtered, lyophilized and stored at $-20^{\circ} \mathrm{C}$, yielding around $10 \%$ of the dry weight of starting material. For the experiments described below, the aqueous crude extract was re-suspended in distilled water. In the case of the antimicrobial assays, it was sterilized by filtration using a $0.22 \mu \mathrm{m}$ membrane.

\section{Phytochemical composition}

The lyophilized crude aqueous extract was submitted to HPLC/DAD analyses, according to a protocol devised by Peng et al. [13] to analyze procyanidins in grape seeds. Samples $(20 \mu \mathrm{l})$ were loaded onto a 4.6 x $250 \mathrm{~mm}$ reverse phase RP-18 column (250 mm X 4,6 mm X $5 \mu \mathrm{m}$; $\left.\mathrm{XTerra}^{\oplus}\right)$. Elution was achieved with solvents A $(0.02 \%$ phosphoric acid in water) and B (82\% acetonitrile, $0.04 \%$ phosphoric acid) as follows: 0 to $15 \%$ solvent $\mathrm{B}$ in the first $15 \mathrm{~min}, 15$ to $16 \%$ from 15 to $40 \mathrm{~min}, 16$ to $17 \%$ from 40 to $45 \mathrm{~min}, 17$ to $43 \%$ from 45 to $48 \mathrm{~min}, 43$ to $52 \%$ from 48 to $49 \mathrm{~min}$, held isocratic at $52 \%$ from 49 to $56 \mathrm{~min}$, reduced from 52 to $43 \%$ from 56 to $57 \mathrm{~min}$, and from 17 to $0 \%$ from 58 to $60 \mathrm{~min}$. Peaks were detected at $280 \mathrm{~nm}$.

The concentration of procyanidins in the sample solution of $C$. nucifera lyophilized crude aqueous extract was determined by the vanillin- $\mathrm{HCl}$ assay [14]. Briefly, $2.5 \mathrm{ml}$ of methanol (control) or $1 \%$ vanillin solution in methanol (sample) and $2.5 \mathrm{ml}$ of $9 \mathrm{M} \mathrm{HCl}$ in methanol was added to a test tube containing $1 \mathrm{ml}$ of catechin solution ( 0 to $300 \mu \mathrm{g} / \mathrm{ml}$ in methanol) or test solution (150 to $250 \mu \mathrm{g} / \mathrm{ml}$ polyphenols in methanol). The reaction mixture was incubated for $20 \mathrm{~min}$ at $30^{\circ} \mathrm{C}$, and the absorbance at $500 \mathrm{~nm}$ was measured. The absorbance was calculated as follows for each standard and sample solution: a calibration curve was prepared using the calculated absorbance for the catechin solution, and the total procyanidin in each test solution was calculated from the calibration curve.

\section{Animals}

All experiments were performed with male Swiss mice (20-25 g) obtained from our own animal facility. Animals were maintained in temperature-controlled room $\left(22 \pm 2^{\circ} \mathrm{C}\right)$ with a $12 \mathrm{~h}$ light/dark cycles and free access to food and water. Twelve hours prior to each experiment, the animals received only water in order to avoid food interfering with the substance absorption. Animal care and research protocols (ICBDFBC-015) were in accordance with the principles and guidelines adopted by the Brazilian College of Animal Experimentation (COBEA), approved by the Ethical Committee for Animal Research (Biomedical Science Institute/UFRJ).

\section{Drugs and extract administration}

Acetylsalicylic acid (ASA) and morphine hydrochloride were purchased from Sigma (St. Louis, MO, USA) and Merck Inc. (Brazil), respectively. They were dissolved in sterile water just before use. The extract was dissolved in sterile water and administered by oral gavage at doses of 10,50 , and $100 \mathrm{mg} / \mathrm{kg}$ in a final volume of $0.1 \mathrm{ml}$. Morphine $(1 \mathrm{mg} / \mathrm{kg})$ and ASA $(100 \mathrm{mg} / \mathrm{kg})$ were used as reference drugs and were also administered by oral gavage. The negative control group received vehicle by oral gavage. 


\section{Formalin test}

The formalin test was conducted in a manner similar to that described by Gomes et al. [15]. Animals received an injection of $20 \mu \mathrm{l}$ of formalin $(2.5 \% \mathrm{v} / \mathrm{v})$ into the dorsal surface of the left hind paw. The time that the animal spent licking the injected paw was recorded. The response consists of two phases. The first phase occurs $5 \mathrm{~min}$ immediately following the formalin injection (neurogenic pain response), and the second phase occurs 15-30 min after formalin injection (inflammatory pain response). The animals were pretreated with oral doses of extract, ASA, morphine or vehicle $60 \mathrm{~min}$ before the injection of formalin.

\section{Subcutaneous air pouch (SAP) model}

The method was similar to that described by Romano et al. [16] with several modifications described in Raymundo et al. [17]. Briefly, air pouches were produced by subcutaneous injection of sterile air $(10 \mathrm{ml})$ into the intrascapular region of the mice. After three days, another injection of air $(10 \mathrm{ml})$ was performed in order to maintain the pouches. Three days after the last injection of air, animals received an injection of sterile carrageenan suspension (1\%) into the SAP. Mice were pre-treated with oral doses of extract, ASA or vehicle $1 \mathrm{~h}$ before and $23 \mathrm{~h}$ after carrageenan injection in the SAP. Animals were sacrificed $24 \mathrm{~h}$ after carrageenan injection and the cavity was washed with $1 \mathrm{ml}$ of sterile PBS. The total number of cells was determined with the aid of a haemocytometer. The exudates were centrifuged at $170 \mathrm{x} \mathrm{g}$ for $10 \mathrm{~min}$ at $4^{\circ} \mathrm{C}$, and the supernatants were collected and stored at $-20^{\circ} \mathrm{C}$ to further analysis. Supernatants from exudates collected in the SAP were used to measure tumor necrosis factor- $\alpha$ (TNF- $\alpha$ ) and protein. TNF- $\alpha$ was quantified by enzyme-linked immunosorbent assay (ELISA), using the protocol supplied by the manufacturer (B\&D, USA). The protein content of each supernatant was determined using the BCA method $\left(\mathrm{BCA}^{\mathrm{TM}}\right.$ Protein Assay Kit, Pierce).

\section{Antioxidant activity determined by the 2,2-diphenyl-1- picryl-hydrazyl-hydrate (DPPH) photometric assay}

The free radical scavenging activity of the $C$. nucifera extract was evaluated as described by Mensor et al. [18]. Briefly, the plant extract was mixed with a 0.3 $\mathrm{mM}$ 2,2-Diphenyl-1-picryl-hydrazyl-hydrate (DPPH) ethanol solution, to give final concentrations of 0.78 , $1.56,3.13,6.25,12.5,25,50$, and $100 \mu \mathrm{g}$ of extract per $\mathrm{ml}$ of $\mathrm{DPPH}$ solution. After $30 \mathrm{~min}$ at room temperature, the absorbance values were measured at $518 \mathrm{~nm}$ and converted into the percentage of antioxidant activity. Free radical scavenging activity of the extract was compared with those of the quercetin, rutin, and ascorbic acid.

\section{Microorganisms and antimicrobial standards}

Methicillin and vancomicin were obtained from SigmaAldrich (Brazil) and stored according to the supplier's instructions. The following reference strains were used: Staphylococcus aureus ATCC 6538 and the fungus Candida albicans ATCC 36802. The study also included a methicillin-resistant Staphylococcus aureus strain (BMB 9393) and a clinical isolate of Escherichia coli obtained from University Hospital of the Federal University of Rio de Janeiro.

\section{Antimicrobial activities}

The antimicrobial activity of the $C$. nucifera extract was evaluated by the agar diffusion method described by Hili et al. [19]. Microorganisms ( 2 x $10^{5}$ cells) were spread over appropriate plate (Brain Heart Infusion agar for bacteria and Sabouraud agar for the fungus). The extract was diluted in water $(10 \mathrm{mg} / \mathrm{ml})$, sterilized by filtration, and $10 \mu \mathrm{l}$ aliquots of aqueous crude extract were applied to newly inoculated plates. Plates were incubated at $37^{\circ} \mathrm{C}$ for $24 \mathrm{~h}$ (bacteria) or for $48 \mathrm{~h}$ at room temperature (fungus).

\section{Minimal inhibitory concentration (MIC) and minimal bactericidal concentration (MBC) assays}

The MICs values of the extract against the test microorganisms were determined by broth microdilution method as recommended by CLSi [20]. The microdilution method was also used to determine MBC values. The substances were transferred to a microplate in order to obtain twofold serial dilutions of the original substance. Then, an inoculum $(10 \mu \mathrm{l})$ containing $5 \times 10^{6} \mathrm{CFU} / \mathrm{ml}$ was added to each well and the microplates were aerobically incubated at $37^{\circ} \mathrm{C}$ for $24 \mathrm{~h}$. Wells without inoculum added were used for sterility control, and the positive controls comprised of inoculated growth medium without the substances.

Bacterial growth was indicated by the presence of turbidity and a pellet on the well bottom, which was confirmed with $30 \mu \mathrm{l}$ of resazurin (Sigma-Aldrich) added aseptically and incubated at $37^{\circ} \mathrm{C}$ for $1 \mathrm{~h}$. The MIC was defined as the lowest extract concentration that was able to completely inhibit the bacterial growth. Methicillin and vancomicin were used as antimicrobial standards.

To evaluate whether the action of the extract was microbiostatic or microbicidal, $20 \mu \mathrm{l}$ of the microbial culture were removed from wells with concentrations equal to, or higher than, the MIC, inoculated on BHI agar plates, and incubated at $37^{\circ} \mathrm{C}$ for $24 \mathrm{~h}$. The $\mathrm{MBC}$ was defined as the lowest extract concentration at which all of the bacteria have been killed.

\section{Synergistic activity of the extract and antimicrobial drugs against microorganisms}

According to Mahboubi and Bidgoli [21], synergistic antimicrobial activity was evaluated by a checkerboard 
assay with the broth microdilution method. The extract and commercial antimicrobials were combined in concentrations lower than their individual MIC values by serial dilution in microplates. An inoculum $(10 \mu \mathrm{l})$ containing $5 \times 10^{6} \mathrm{CFU} / \mathrm{ml}$ was added to each well and the microplates were incubated at $37^{\circ} \mathrm{C}$ for $24 \mathrm{~h}$. The visual bacterial growth was confirmed with $30 \mu \mathrm{l}$ of resazurin (Sigma-Aldrich) added aseptically and incubated at $37^{\circ} \mathrm{C}$ for $1 \mathrm{~h}$.

Fractional inhibitory concentrations (FICs) were calculated as the MIC of the combination of the extract and a commercial antimicrobial divided by the MIC achieved when one of them was used individually. FIC index is widely accepted for use in evaluating in vitro synergistic actions. It is the sum of FICs values and indicates the nature of an interaction between two compounds. A FIC index between 0.5 and 4.0 indicates an insignificant interaction, whereas FIC index values $<0.5$ and $>4.0$ have synergistic and antagonistic interactions, respectively.

\section{Statistical analysis}

In vitro experiments (antimicrobial and antioxidant assays) were undertaken in triplicate sets. All animal groups were composed of 6-10 mice and the results are presented as the mean \pm S.D. Statistical significance between groups was determined by analyses of variance (ANOVA) followed by Bonferroni's test. $p$ values less than $0.05\left({ }^{*} p<0.05\right)$ were considered significant.

\section{Results and discussion}

\section{Phytochemical composition}

Application of the reverse phase C18 HPLC protocol devised by Peng et al. [13] to the crude aqueous extract produced the chromatogram shown in Figure 1. The broad peak at 50-55 min belongs to a mixture of polymeric procyanidins. This elution behavior and UV absorption characteristics indicate the presence of condensed tannins [13].

In order to corroborate the presence of these tannins, the vanillin- $\mathrm{HCl}$ assay was performed. This test is highly specific for procyanidins and involves acidic hydrolysis of the condensed tannins followed by coupling of the flavanol units to vanillin. Polymeric procyanidins were detected at a concentration of $103.80 \pm 10.5 \mathrm{mg} / \mathrm{g}$ of aqueous extract.

\section{Anti-inflammatory activity}

Initially, the anti-inflammatory effect of the extract was evaluated by the formalin-induced licking model. The response consists of two phases and can evaluate both antinociceptive and anti-inflammatory activities. Centrally acting drugs, such as narcotics, are able to inhibit the two phases equally. The first phase involves direct chemical stimulation of nociceptive afferent fibers, leading to acute neurogenic pain. However, the second phase involves inflammation in the paw and central sensitization [22,23].

As depicted in Figure 2, extract treatment did not reduce the time that the animal spent licking the formalininjected paw during the first phase (neurogenic pain response). However, during the second phase (inflammatory pain response), extract treatment induced dose-dependent inhibition, indicating an anti-inflammatory effect. Therefore, the extract could be acting through inhibition of the formation and/or liberation of inflammatory mediators or by directly blocking its receptor. In order to evaluate how the extract could inhibit the inflammatory reaction, another model of inflammation was performed, the subcutaneous air pouch. This model was not achieved by previous studies with aqueous extract of husk fiber from $C$. nucifera. In this model, subcutaneous injections of air into the back result in

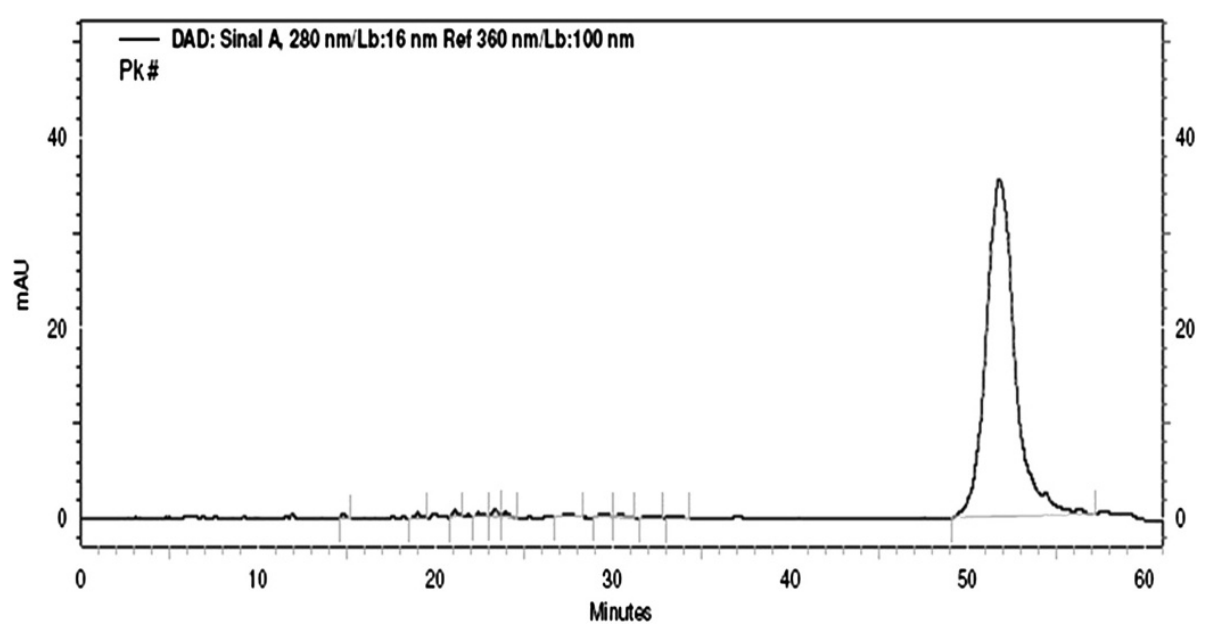

Figure 1 A trace of reverse phase HPLC analysis of $\boldsymbol{C}$. nucifera lyophilized crude aqueous extract. The asterisk $\left(^{*}\right)$ in the figure indicates polymeric procyanidins. 


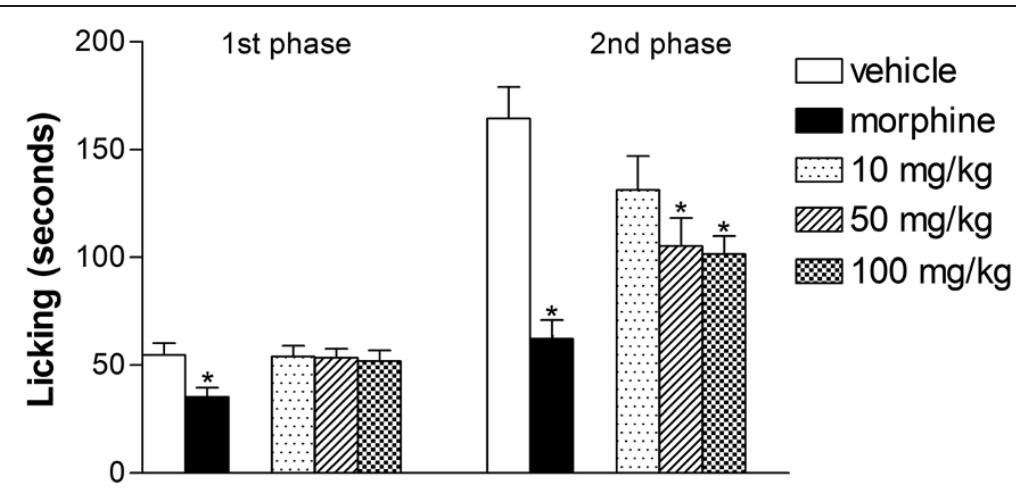

Figure 2 Effects of the $C$. nucifera extract on formalin-induced licking in mice. Animals were pretreated by oral administration different doses of the $C$. nucifera extract, morphine $(1 \mathrm{mg} / \mathrm{kg})$, or vehicle. The results are presented as mean \pm S.D. $(n=6-10)$ of the time that the animals spent licking the formalin-injected paws. Statistical significance was calculated by ANOVA followed by Bonferroni's test. ${ }^{*}$ indicates $p<0.05$ when comparing to the vehicle-treated group.

formation of a cavity similar to the synovium and the injection of carrageenan in this cavity induces inflammation. The site serves as a reservoir of cells and mediators that can be measured in the locally accumulating fluid [24].

Injection of carrageenan (1\%) into the mice air pouches increased the number of leukocytes that migrated to the cavity when compared to the control that received PBS in the SAP. Pre-treatment with lower dose of the extract $(10 \mathrm{mg} / \mathrm{kg})$ was not able to significantly reduce the number of leukocytes. However, pre-treatment with

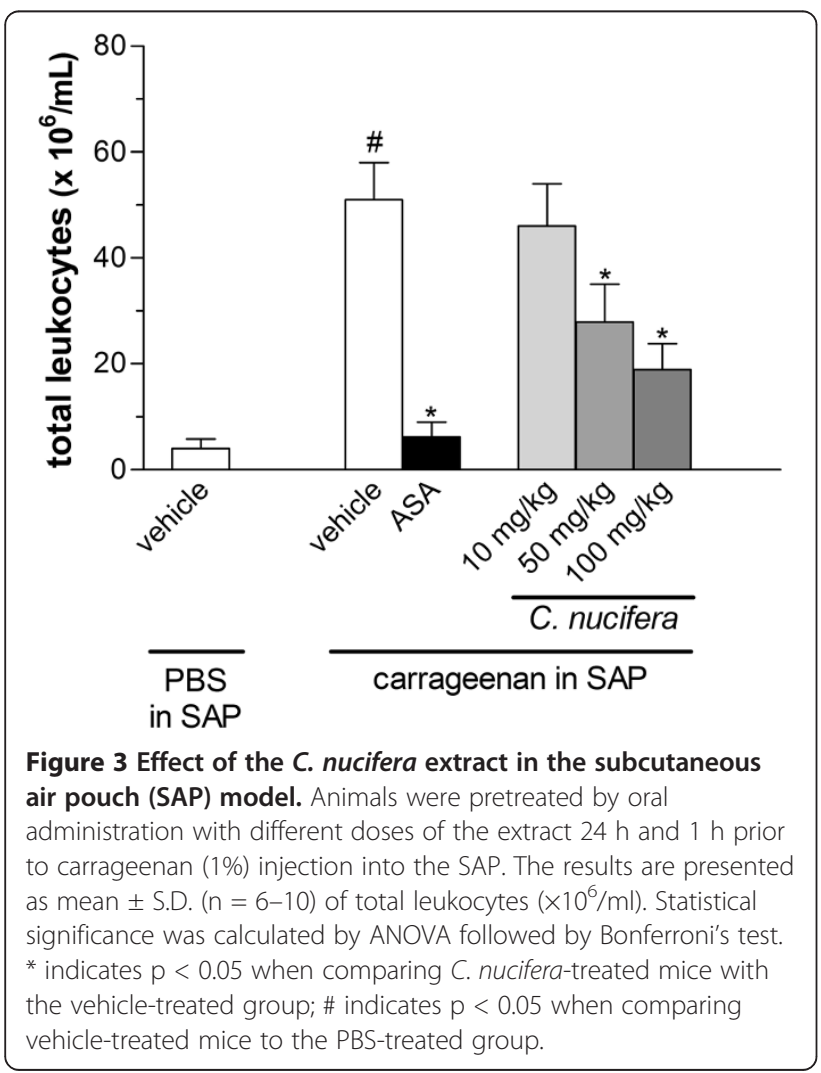

the other doses of extract (50 or $100 \mathrm{mg} / \mathrm{kg}$ ) significantly suppressed the cell migration (Figure 3).

A similar pattern was observed in the exudates protein concentrations. An increase in the levels of protein was detected following carrageenan injection in the SAP. This carrageenan-induced protein leakage was significantly inhibited by pre-treatment with the higher doses of extract (50 or $100 \mathrm{mg} / \mathrm{kg}$ ) (Figure 4). These effects could be due to disruption of inflammatory mediators' formation or by inhibition of receptor function.

One of the mediators that play an important role in the inflammatory process is TNF- $\alpha$. It is released from

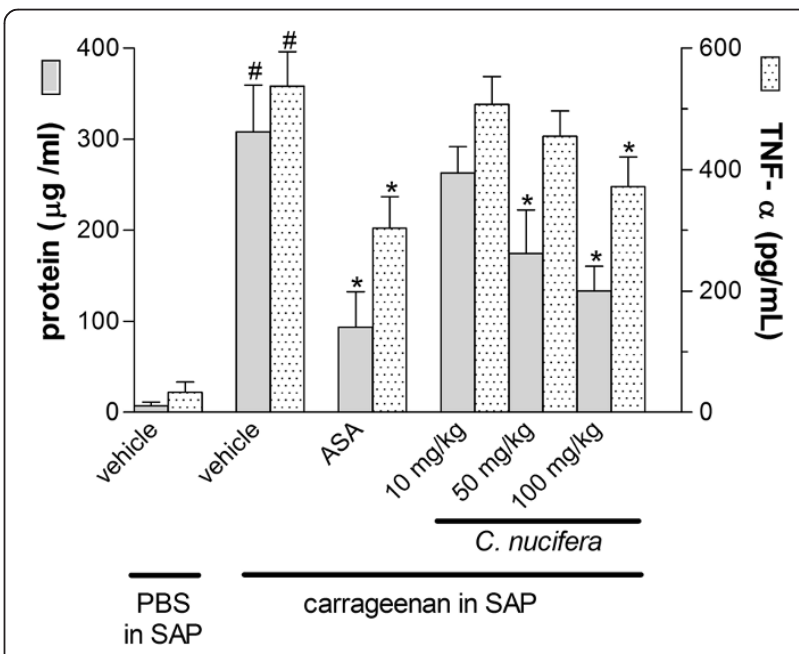

Figure 4 Effect of the $C$. nucifera extract on protein leakage and TNF-a production. Animals were pretreated by oral administration with different doses of the extract $24 \mathrm{~h}$ and $1 \mathrm{~h}$ prior to carrageenan (1\%) injection into the subcutaneous air pouch (SAP). The results are presented as mean \pm S.D. $(n=6-10)$ of protein $(\mu \mathrm{g} / \mathrm{ml})$ or TNF-a $(\mathrm{pg} / \mathrm{ml})$. Statistical significance was calculated by ANOVA followed by Bonferroni's test. ${ }^{*}$ indicates $p<0.05$ when comparing $C$. nucifera-treated mice with the vehicle treated group; \# indicates $p<0.05$ when comparing vehicle-treated mice with the PBS-treated group. 


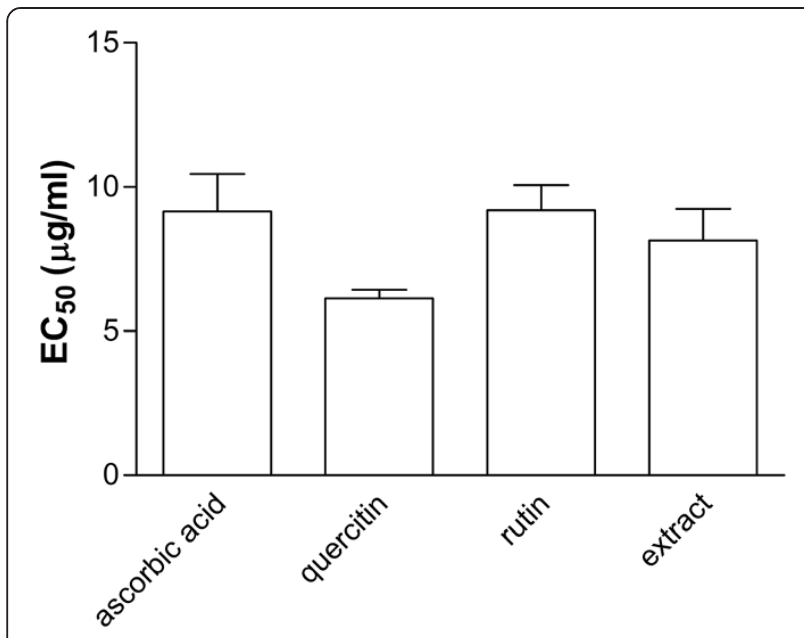

Figure 5 Free radical scavenging properties of the $C$. nucifera extract, using the DPPH photometric assay. The results are presented as mean \pm S.D. from three independent assays. EC50 values were determined.

activated monocytes and macrophages and increases vascular endothelial permeability [25]. The production of this mediator was dramatically increased by the injection of carrageenan in the SAP. Nevertheless, the levels of this mediator in the exudates were significantly reduced in mice that received pre-treatment with the highest dose of extract (100 mg/kg) (Figure 4).

\section{In vitro antioxidant activity}

The antioxidant activity was determined by the 2,2diphenyl-1-picryl-hydrazyl-hydrate (DPPH) assay. The $\mathrm{EC}_{50}$ values were calculated, and the result obtained for the C. nucifera extract was comparable with those of the standards (quercetin, rutin, and ascorbic acid) (Figure 5).

A good antioxidant effect of the aqueous crude extract of husk fiber from "olho de cravo" C. nucifera has already been determined by the same model $\left(\mathrm{EC}_{50}=10.0 \pm 0.7 \mu \mathrm{g} / \mathrm{ml}\right)$. This activity could be attributed to the presence of condensed tannins in the husk fiber from C. nucifera [11].

Nevertheless, the extrapolation of an antioxidant effect in vitro to an in vivo action is not trivial. A

Table 1 Antimicrobial screening of $C$. nucifera extract by agar diffusion method

\begin{tabular}{ll}
\hline Microorganism & Antimicrobial screening \\
\hline C. albicans & - \\
\hline E. coli & - \\
\hline S. aureus & + \\
\hline MRSA & + \\
\hline
\end{tabular}

(-) no activity; (+) activity.
Table 2 Minimal inhibitory concentrations (MICs) of $C$. nucifera extract and antimicrobial drugs by the microdilution method

\begin{tabular}{lccc}
\hline Microorganism & \multicolumn{3}{c}{ MIC* $(\boldsymbol{\mu g} / \mathbf{m L})$} \\
\cline { 2 - 4 } & extract & MET & VCM \\
\hline S. aureus & 1024 & 0,25 & nd \\
\hline MRSA & 1024 & 512 & 1 \\
\hline * All MICs were microbicidal; & MET - methicillin; VCM - vancomycin; nd - not
\end{tabular}

* All MICs were microbicidal; MET - methicillin; VCM - vancomycin; nd - not determined.

direct antioxidant activity of flavonoids in vivo is likely to be limited to tissues in which relatively high concentrations of these compounds could be achieved, like in the digestive tract. In lower concentrations, they could support indirect antioxidant actions, like regulation of pro-oxidant enzymes and inhibition of protein-receptor coupling that initiates oxidant production [26].

However, the antioxidant activity can be related to an anti-inflammatory effect. Free radicals can attract inflammatory mediators contributing to a generalized inflammatory response [27]. The reactive oxygen species are linked to increased endothelial permeability and leukocyte transendothelial migration [28]. This can explain the inhibition of the carrageenan-induced protein leakage and the leukocyte migration by the extract of $C$. nucifera in the SAP.

\section{Antimicrobial activity}

The results of the agar diffusion assay showed that the extract does not have an antimicrobial effect against the fungus and the Gram-negative bacterium tested. However, an inhibition zone was observed when the extract was tested against $S$. aureus and MRSA (Table 1).

Esquenazi et al. [2] found that the "olho de cravo" $C$. nucifera has activity against one $S$. aureus ATCC strain and three clinical isolates of $S$. aureus. Further, Akinyele et al. [9] studied the aqueous extracts of the husk fiber from a $C$. nucifera variety from Nigeria. They demonstrated that it also has activity against $S$. aureus, in addition to inhibiting Gram-negative bacteria, such as Escherichia coli.

In accordance to the lack of reported activity of $C$. nucifera against Candida albicans in the literature, the

Table 3 Effects of combinations of antimicrobial drugs and $C$. nucifera extract against MRSA

\begin{tabular}{lccccc}
\hline & $\begin{array}{c}\text { MIC of drug in } \\
\text { combination }\end{array}$ & $\begin{array}{c}\text { MIC of extract in } \\
\text { combination }\end{array}$ & $\begin{array}{c}\text { FIC of } \\
\text { drug }\end{array}$ & $\begin{array}{c}\text { FIC of } \\
\text { extract }\end{array}$ & $\begin{array}{c}\text { FIC } \\
\text { index }\end{array}$ \\
\hline VCM & 0,9375 & 256 & 0,9375 & 0,25 & $1,19(\mathrm{I})$ \\
\hline MET & 96 & 256 & 0,1875 & 0,25 & $0,44(\mathrm{~S})$ \\
\hline
\end{tabular}

VCM - vancomicin; MET - methicillin; MIC - minimal inhibitory concentration $(\mu \mathrm{g} / \mathrm{ml})$; FIC -fractional inhibitory concentration; I- indifferent; $\mathrm{S}$ - synergistic. 
"gigante" variety does not have effect against this fungus. Despite of being the same species of coconut, the different varieties have different types and quantities of substances in the fiber. The biological activity can be affected by structural variations, such as stereochemistry [29].

This may be the reason why the "gigante" variety does not have the same effects of the variety from Nigeria described by Akinyele et al. [9]. In the present paper, the extract does not possess growth inhibitory activity against Escherichia coli. Nevertheless, it is important to note that the tested strain is different from that of the other study. Discrepancy in findings may be the result of the pathogen strains utilized or also be due to the variety of the plant and extraction process used.

Others varieties have activity against $S$. aureus and the "gigante" variety is likewise active. It was also investigated if it would be able to inhibit the MRSA growth and it was. Thus, the minimal inhibitory concentrations of the extract against those bacteria ( $S$. aureus and MRSA) were determined and results are shown in Table 2.

MIC was the same for the two bacteria strains tested $(1024 \mu \mathrm{g} / \mathrm{ml})$ and at this concentration, a microbicidal effect was observed. MIC values were also determined for methicillin. Methicillin-resistant staphylococcal is defined as MIC $\geq 4 \mu \mathrm{g} / \mathrm{ml}$ [30]. To the methicillin-resistant strain, vancomicin was used as standard antimicrobial.

Despite having been able to killing the two strains of bacteria, the concentration of the extract was higher than those of the standards antimicrobial used. However, the MIC must be interpreted in the appropriate context. The raw extract is a mixture of active and non-active compounds and therefore higher MICs are expected [31].

Cos et al. [32] proposed an endpoint with concentration required to produce $50 \%$ growth inhibition below $100 \mu \mathrm{g} / \mathrm{ml}$ for extracts. Nevertheless, in the present study it was evaluated the extract's concentration that was able to completely inhibit the bacterial growth and not only $50 \%$ growth inhibition. Thus, a higher MIC is acceptable. Webster et al. [31] interpreted a MIC value of crude plant extracts approximately to $1000 \mu \mathrm{g} / \mathrm{ml}$ as showing strong antifungal potential.

The antimicrobial activity may be enhanced by synergistic effect of natural products and antimicrobial drugs. Therefore, the checkerboard assay was performed to evaluate the antimicrobial effects of combinations of antimicrobial drugs and the extract against MRSA. When the extract was combined with vancomycin, the MIC of the extract against MRSA reduced 4-fold, however the MIC of vancomycin against MRSA was almost the same. In this combination, the FIC index was 1.19, corresponding to an indifferent effect (Table 3).
Nevertheless, the MIC value of methicillin against MRSA was lowered from 512 to $96 \mu \mathrm{g} / \mathrm{ml}$ when the extract was added at a concentration of $256 \mu \mathrm{g} / \mathrm{ml}$ (4-fold reduction in MIC). This combination had a FIC index calculated as 0.44 , corresponding to a synergistic effect (Table 3). However, this synergistic effect was not able to reverse the methicillin resistance ( $\mathrm{MIC}$ remained $>4 \mu \mathrm{g} / \mathrm{ml}$ ).

The extract can be fractionated in order to check if the activity improved. In addition, the active substances in the extract and their modes of action should be further investigated. Moreover, the extract can lead to the development of novel inexpensive phytomedicines or models for synthetic substances.

The antistaphylococcal effect of the extract is important because MRSA and vancomycin-intermediate $S$. aureus are spreading worldwide and the pharmaceutical arsenal available to control antimicrobial-resistant bacteria is limited. Invasive infections by $S$. aureus are associated with significant morbidity and mortality, creating urgency in the development of new therapies and adjunct treatments that act against the resistant strains [33,34].

\section{Conclusions}

Concerning the crude nature of the extract, the results allow concluding that it exhibited significant bioactivity and properties that support its uses in the folk medicine. The extract exhibits anti-inflammatory activity through the inhibition of the cell migration. In addition, the mixture of extract constituents and methicillin could lead to the development of a new combination antibiotic against MRSA infections.

Although the modes of action remain to be completely elucidated, the extract and its constituents might be promising candidates for the direct or adjunct treatment of inflammation and infection by MRSA, with low cost.

\section{Competing interests}

The authors declare that they have no competing interests.

\section{Authors' contributions}

RRS carried out all the experiments and wrote the manuscript; DOS prepared and characterized the $C$. nucifera extracts; HRF identificated the C. nucifera variety, collected the seeds and extracted the fibers; CSA participated in the design of the study and revised it critically for important intellectual content; PDF participated in the design of the pharmacological study, helped to draft the manuscript and revised it; DAS participated in the design and coordination of the microbiological study. All authors read and approved the final manuscript.

\section{Acknowledgements}

We would like to thank Renata S. Zardo (M.Sc.) for assistance in SAP model. Authors would like to thank Mr. Mark English for the English revision of the manuscript. The present work was supported by Coordenação de Aperfeiçoamento de Pessoal de Nível Superior (CAPES), Conselho Nacional de Desenvolvimento Científico e Tecnológico (CNPq), and Fundação de Amparo a Pesquisa do Estado do Rio de Janeiro (FAPERJ). 


\section{Author details}

'Universidade Federal do Rio de Janeiro, Instituto de Microbiologia Paulo de Góes, Laboratório de Estruturas de Superfície de Micro-organismos, Instituto de Microbiologia Paulo de Góes, Rio de Janiero, Brasil. ${ }^{2}$ Universidade Federal do Rio de Janeiro, Instituto de Ciências Biomédicas, Laboratório de Farmacologia da Dor e da Inflamação, Rio de Janeiro, Brasil. ${ }^{3}$ Embrapa Tabuleiros Costeiros, Av. Beira Mar 3250 Caixa postal 44. Cep 49015-040, Bairro Treze de Julho, Aracaju, Sergipe, Brasil.

Received: 1 November 2012 Accepted: 8 May 2013

Published: 16 May 2013

\section{References}

1. Adebayo J, Santana A, Krettli A: Evaluation of the antiplasmodial and cytotoxicity potentials of husk fiber extracts from Cocos nucifera, a medicinal plant used in Nigeria to treat human malaria. Hum ExpToxicol 2012, 31:244-249.

2. Esquenazi D, Wigg MD, Miranda MM, Rodrigues HM, Tostes JB, Rozental S, Da Silva AJ, Alviano CS: Antimicrobial and antiviral activities of polyphenolics from Cocos nucifera Linn. (Palmae) husk fiber extract. Res Microbiol 2002, 153:647-652.

3. Alviano DS, Rodrigues KF, Leitão SG, Rodrigues ML, Matheus ME, Fernandes PD, Antoniolli AR, Alviano CS: Antinociceptive and free radical scavenging activities of Cocos nucifera L. (Palmae) husk fiber aqueous extract. J Ethnopharmacol 2004, 92:269-273.

4. Kirszberg C, Esquenazi D, Alviano CS, Rumjanek VM: The effect of a catechin-rich extract of Cocos nucifera on lymphocytes proliferation. Phytother Res 2003, 17:1054-1058.

5. Koschek PR, Alviano DS, Alviano CS, Gattass CR: The husk fiber of Cocos nucifera L. (Palmae) is a source of anti-neoplastic activity. Braz J Med Bio Res 2007, 40:1339-1343.

6. Rinaldi S, Silva DO, Bello F, Alviano CS, Alviano DS, Matheus ME, Fernandes PD: Characterization of the antinociceptive and anti-inflammatory activities from Cocos nucifera L. (Palmae). J Ethnopharmacol 2009, 122:541-546.

7. Ferrero-Miliani L, Nielsen OH, Andersen PS, Girardin SE: Chronic inflammation: importance of NOD2 and NALP3 in interleukin-1beta generation. Clin Explmmunol 2007, 147:227-235.

8. Hordijk PL: Endothelial signaling events during leukocyte transmigration. FEBS J 2006, 273:4408-4415.

9. Akinyele TA, Okoh OO, Akinpelu DA, Okoh Al: In vitro antibacterial properties of crude aqueous and n-hexane extracts of the husk of Cocos nucifera. Molecules 2011, 16:2135-2145.

10. Lin RD, Chin YP, Hou WC, Lee MH: The effects of antibiotics combined with natural polyphenols against clinical methicillin-resistant Staphylococcus aureus (MRSA). PlantaMedica 2008, 74:840-846.

11. Alviano WS, Alviano DS, Diniz CG, Antoniolli AR, Alviano CS, Farias LM, Carvalho MA, Souza MM, Bolognese AM: In vitro antioxidant potential of medicinal plant extracts and their activities against oral bacteria based on Brazilian folk medicine. Arch Oral Biol 2008, 53:545-552.

12. Aragão WM, Tupinambá EA, Angelo PCS, Ribeiro FE: Seleção de cultivares de coqueiro para diferentes ecossistemas do Brasil. In Recursos Genéticos e Melhoramento de Plantas para o Nordeste Brasileiro (online). Edited by Queiroz MA, Goedert CO, Ramos SSR. Petrolina: Embrapa Semi-Árido/ Embrapa Recursos Genéticos e Biotecnologia; 1999

13. Peng Z, Hayasaka Y, lland PG, Sefton M, Høj P, Waters EJ: Quantitative analysis of polymeric procyanidins (Tannins) from grape (Vitis vinifera) seeds by reverse phase high-performance liquid chromatography. J Agric Food Chem 2001, 49:26-31.

14. Nakamura Y, Tsuji S, Tonogai Y: Analysis of Proanthocyanidins in Grape Seed Extracts, Health Foods and Grape Seed Oils. J Heal Sci 2003, 49:45-54.

15. Gomes NM, Rezende CM, Fontes SP, Matheus ME, Pinto AC, Fernandes PD: Characterization of the antinociceptive and anti-inflammatory activities of fractions obtained from Copaifera multijuga Hayne. J Ethnopharmacol 2010, 128:177-183.

16. Romano M, Faggioni R, Sironi M, Sacco S, Echtenacher B, Di Santo E, Salmona M, Ghezzi P: Carrageenan-induced acute inflammation in the mouse air pouch synovial model. Role of tumour necrosis factor. Med Inflam 1997, 6:32-38.
17. Raymundo LJ, Guilhon CC, Alviano DS, Matheus ME, Antoniolli AR, Cavalcanti SC, Alves PB, Alviano CS, Fernandes PD: Characterization of the anti-inflammatory and antinociceptive activities of the Hyptis pectinata (L.) Poit essential oil. J Ethnopharmacol 2011, 134:725-732.

18. Mensor LL, Menezes FS, Leitão GG, Reis AS, Dos Santos TC, Coube CS, Leitão SG: Screening of Brazilian plant extracts for antioxidant activity by the use of DPPH free radical method. Phytother Res 2001, 15:127-130.

19. Hili $P$, Evans CS, Veness RG: Antimicrobial action of essential oils: the effect of dimethylsulphoxide on the activity of cinnamon oil. Lett App Microbiol 1997, 24:269-275.

20. Clinical and Laboratory Standards Institute (CLSi): Methods for Dilution Antimicrobial Susceptibility Tests, fourth ed. Wayne, PA, USA; 2008. Approved Standard, M7-A4.

21. Mahboubi M, Bidgoli FG: Antistaphylococcal activity of Zataria multiflora essential oil and its synergy with vancomycin. Phytomedicine 2010, 17:548-550

22. Ocvirk R, Murphy P, Franklin KB, Abbott FV: Antinociceptive profile of ring A-reduced progesterone metabolites in the formalin test. Pain 2008, 138:402-409.

23. Shibata M, Ohkubo T, Takahashi H, Inoki R: Modified formalin test: characteristic biphasic pain response. Pain 1989, 38:347-352.

24. Shin S, Jeon JH, Park D, Jang JY, Joo SS, Hwang BY, Choe SY, Kim Y: Anti-inflammatory effects of an ethanol extract of Angelica gigas in a carrageenan-air pouch inflammation model. Exp Animals 2009, 58:431-436

25. Mehta D, Malik AB: Signaling Mechanisms Regulating Endothelial Permeability. Physiol Rev 2006, 86:279-367.

26. Fraga CG, Oteiza Pl: Dietary flavonoids: Role of (-)-epicatechin and related procyanidins in cell signaling. Free Rad Biol Med 2011, 51:813-823.

27. García-Lafuente A, Guillamón E, Villares A, Rostagno MA, Martínez JA: Flavonoids as anti-inflammatory agents: implications in cancer and cardiovascular disease. Inflam Res 2009, 58:537-552.

28. Wittchen ES: Endothelial signaling in paracellular and transcellular leukocyte transmigration. Front Biosc 2009, 14:2522-2545.

29. Kusuda M, Inada K, Ogawa TO, Yoshida T, Shiota S, Tsuchiya T, Hatano T: Polyphenolic constituent structures of Zanthoxylum piperitum fruit and the antibacterial effects of its polymeric procyanidin on methicillinresistant Staphylococcus aureus. Biosc Biotechnol Biochem 2006, 70:1423-1431.

30. Clinical and Laboratory Standards Institute (CLSi): Performance standards for antimicrobial susceptibility testing, 18th informational supplement. Wayne, PA, USA: CLSI; 2008. document M100-S18.

31. Webster D, Taschereau P, Belland RJ, Sand C, Rennie RP: Antifungal activity of medicinal plant extracts; preliminary screening studies. J Ethnopharmacol 2008, 115:140-146.

32. Cos P, Vlietinck AJ, Berghe DV, Maes L: Anti-infective potential of natural products: how to develop a stronger in vitro 'proof-of-concept'. J Ethnopharmacol 2006, 106:290-302.

33. Van Bambeke F, Mingeot-Leclercq MP, Struelens MJ, Tulkens PM: The bacterial envelope as a target for novel anti-MRSA antibiotics. Trends in Pharmacolsc 2008, 29:124-134.

34. Zampini IC, Cuello S, Alberto MR, Ordoñez RM, D' Almeida R, Solorzano E, Isla Ml: Antimicrobial activity of selected plant species from "the Argentine Puna" against sensitive and multi-resistant bacteria. J Ethnopharmacol 2009, 24:499-505.

doi:10.1186/1472-6882-13-107

Cite this article as: Silva et al:: Anti-inflammatory, antioxidant, and antimicrobial activities of Cocos nucifera var. typica. BMC Complementary and Alternative Medicine 2013 13:107. 